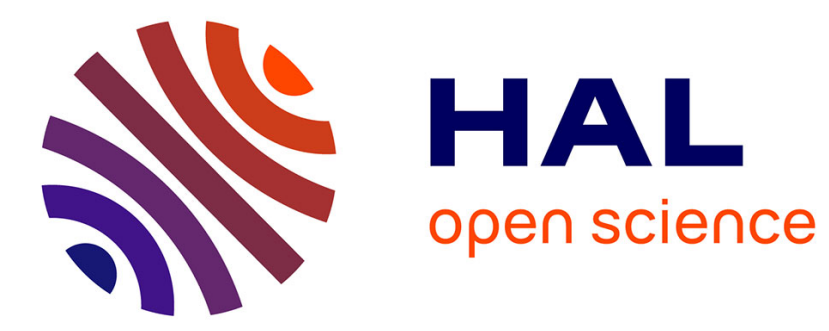

\title{
A microcontroller based wall shear stress measurement
}

Mourad Laghrouche, David Meunier, Jumana Boussey-Said, Sedat F. Tardu, A. Adane

\section{To cite this version:}

Mourad Laghrouche, David Meunier, Jumana Boussey-Said, Sedat F. Tardu, A. Adane. A microcontroller based wall shear stress measurement. IEEE International Symposium on Industrial Electronics, May 2004, Ajaccio, France. 10.1109/ISIE.2004.1571793 . hal-00262264

\section{HAL Id: hal-00262264 https://hal.science/hal-00262264}

Submitted on 7 Feb 2020

HAL is a multi-disciplinary open access archive for the deposit and dissemination of scientific research documents, whether they are published or not. The documents may come from teaching and research institutions in France or abroad, or from public or private research centers.
L'archive ouverte pluridisciplinaire HAL, est destinée au dépôt et à la diffusion de documents scientifiques de niveau recherche, publiés ou non, émanant des établissements d'enseignement et de recherche français ou étrangers, des laboratoires publics ou privés. 


\title{
A Microcontroller Based Wall Shear Stress Measurement
}

\author{
M. Laghrouche ${ }^{1,3}$, D. Meunier ${ }^{1}$, J.Boussey $^{1}$, S. Tardu ${ }^{2}$ and A. Adane ${ }^{3}$ \\ ${ }^{1}$ Institute of Microelectronics. Electromagnetism and Photonics \\ IMEP, ENSERG. 23 rue des Martyrs. 38016 Grenoble Cédex 1. France \\ ${ }^{2}$ Laboratoire des Ecoulements Géophysiques et Industriels. LEGI. INPG-UJF-CNRS \\ B.P. 53 X, 38402 Grenoble Cédex-France \\ ${ }^{3}$ Mouloud Mammeri University. Department of Electronics, \\ Faculty of Engineering. PO Box 17 RP 15000, Tizi Ouzou. Algeria \\ email: laghrouc a enserg.fr $\underline{\text { http://www.imep.enserg.fr }}$
}

\begin{abstract}
A new type of hot wire anemometer was developed by using surface micro machining techniques. The reduction of the microprobes section and the development of a thermal isolation cavity below the hot polycrystalline silicon wire reduced considerably indirect thermal exchanges between the hot wire and its substrate. As a consequence, the response time of the sensor is considerably improved allowing the detection of fast fluctuations and turbulent phenomena in fluid mechanics. In this paper we briefly describe the realisation technology of the developed sensors, its operation principles and the data acquisition circuit especially conceived and realised to perform turbulent flow detection in a low speed wind tunnel.
\end{abstract}

Index Terms-MEMS, sensor data acquisition, wall shear stress sensor.

\section{INTRODUCTION}

The control of turbulence in fluid mechanics is a very important issue which may has strong impact in several industrial fields. The more important one is the civil and military aviation where the reduction of air friction on the delta wings still a big economics stake. Since the early 90 's. several research teams have been working on this application developing either integrated sensors or microactuators that have to be implemented in a specific critical points on the aeroplane. The work presented in this paper is related to a specific type of those sensors, i.e., hot wire anemometers which are usually dedicated for flow speed measurement. In aerodynamics applications, it has been established that hot wire anemometers can be used to detect turbulent mechanisms inside boundary layers, under the only condition to be mounted tangential to the aeroplane surface. The turbulent phenomena induce swirling structures which are a few hundred of microns width and a few millimetres length [1. 2] and have a very short life span (on the order of the millisecond). Classical anemometer (with Platinum wire of $10 \mu \mathrm{m}$ diameter and $400 \mu \mathrm{m}$ length inserted inside macroscopic tubes) [3] were reported to have very good dynamic performance (time response of few milliseconds) but still are incompatible with the need to obtain an array of identi$\mathrm{cal}$, and ultra-miniaturised, sensors The spatial and temporal sensing of the swirling structures (responsible for parietal friction) is a big issue and is made progressively possible thanks to the use of integrated sensors. We will show in the presented work how the use of adapted microtechnologies allowed us to obtain highly miniaturised hot wire ane- mometers. Several microsensors of various geometries were produced by surface micro machining. using thermally sensitive materials like polycrystalline silicon $[4,5]$. The response time was also optimised via a suitable thermal isolation architecture. Finally. electrical and functional (in wind tunnel) characterisations were performed and the firstly obtained results are presented..

\section{REALIZATION OF A SHEAR STRESS SENSOR}

Fig. 1 shows top and cross section scheme of the adopted technology. PECVD (Plasma Enhanced Chemical Vapor Deposition) silicon nitride was first deposited on $p$ type 4 " wafers to a thickness of $0.3 \mu \mathrm{m}$. Then the silicon nitride film was patterned and wet thermal oxidation of silicon was made through the nitride window. Oxidation time was adjusted with technological step simulation for achieving a flat surface. A $0.3 \mu \mathrm{m}$ depth silica cavity was obtained. A $0.5 \mu \mathrm{m}$-thick polycrystalline silicon film was then deposited inside a LPCVD (Low Pressure Chemical Vapor deposition) furnace and doped by boron ions implantation at appropriate parameters (energy and dose of ion implantation were chosen to optimise the thermal sensibility of the soobtained semiconductor. After the thermal annealing. polycrystalline silicon was patterned into to obtain variable section and length of wires.
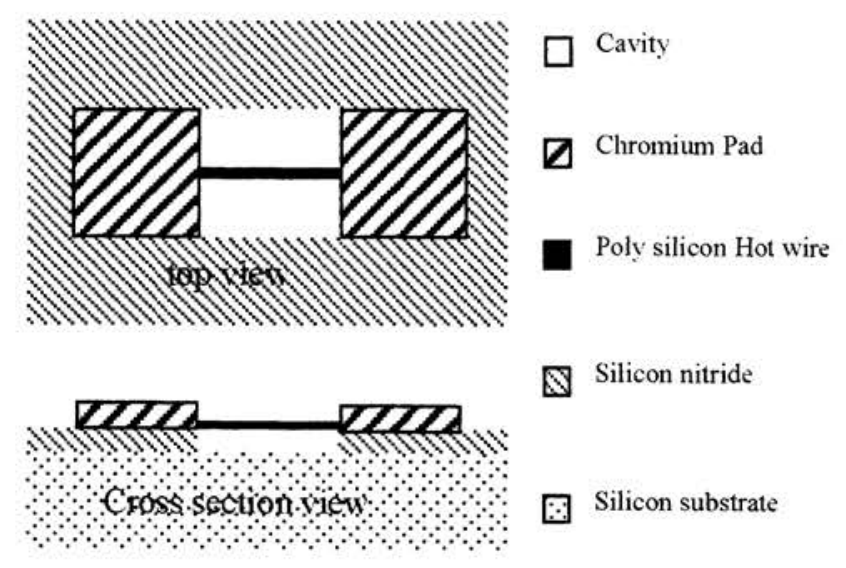

Fig.1 Technological realization of the hot-wire probe suspended on a micro-cavity.

Electrical contacts were finally taken with chromium pads. The whole wafer was then diced into individual chips and releasing of the polysilicon wire was performed by wetetching of the silica cavity performed on each sample. The 
presence of the cavity underneath the wire ensures the more efficient thermal isolation between the hot wire and its substrate. The depth of cavity is only of $0.5 \mu \mathrm{m}$ which prevents the formation of parasitic turbulence inside the cavity [2].

\section{ELECTRIC SENSITIVITY OF THE SENSORS}

The sensors were firstly characterized under 2 points prober, in order to determine their static electrical properties (current-bias characteristics) and their behavior with temperature. Two types of parameters were deduced for each type of sensors:

the resistance variation as a function of the temperature for determining the TCR (Temperature Coefficient Resistance $=\frac{1}{R_{0}} \frac{\partial R}{\partial T}$ where $R_{0}$ is the extrapolated resistance taken at the temperature of $0^{\circ} \mathrm{C}$ ). It was found out that the TCR values are independent of the hot wire geometry and relatively uniform on all the surface of the wafer. An average value of $-0.5 \cdot 10^{-4} /{ }^{\circ} \mathrm{C}$ was measured for samples doped at $10^{16} \mathrm{~cm}^{-2}(80 \mathrm{keV})$ of boron.

The current value to be injected inside the polysilicon wire in order to elevate its temperature. This overheating polarisation current was deduced from TCR value and current-voltage characteristics of each sensor. As an example, for the $0.5 \times 2 \times 50 \mu \mathrm{m}^{3}$ having the above mentioned TCR value, a current of $235 \mu \mathrm{A}$ was used to increase the wire temperature of $70^{\circ} \mathrm{C}$.

\section{A. Dynamic and Electric Time Response}

Although static measurement is founded on a simple principle, it is now accepted that the frequency response of such sensors is in general complex because of convective and conductive heat exchanges. This can be illustrated by the significant difference between the electrical time response and the thermal time response. The electrical time response defined as being the response time of the conductor when it is biased with a perfect square signal (pulse). The electrical time response of the sensor is $3 \mu \mathrm{s}$ (Fig 2).

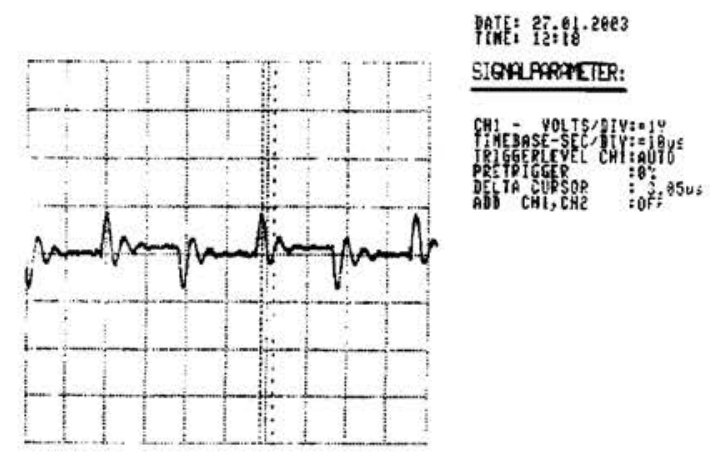

Fig. 2 Electrical time response

An electric circuit based on the internal heating method was designed and carried out for the dynamic response time determination of the sensors (Fig.3)

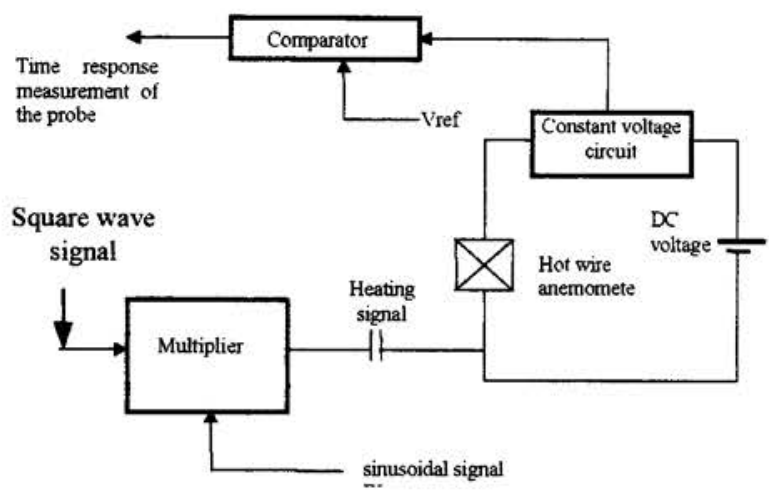

Fig. 3 Time response measurement circuit.

The circuit makes possible to simulate. at the sensor level. the fluctuations of temperature by carning out an internal modulation of the wire heating created by a D.C. current (rated current of the probe). An alternative current. AC. with a frequency of $1 \mathrm{MHz}$ modulated by a square signal with a frequency of $1 \mathrm{kHz}$ is superimposed.

Fig. 4 shows the time response of a $60 \times 2 \times 0.5 \mu \mathrm{m}^{3}$ hot wire, which is about $150 \mu \mathrm{s}$. The bandwidth sensor lies between 0 and $1 \mathrm{KHz}$. This bandwidth is not large enough for detecting all turbulence phenomena associated with airflow over aircraft's.

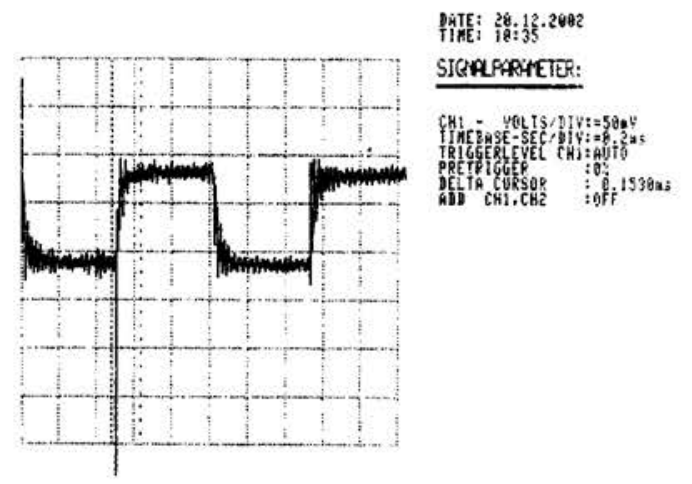

Fig. 4 Time response measurement of a $50 \times 2 \times 0.5 \mu \mathrm{m}^{3}$ wall shear stress sensor.

\section{B. Data Acquisition System}

The Data Acquisition System is composed of two main subsystems: the programmable digital data acquisition system and the sensors with their associated circuits [6]. The requirement of data acquisition system, in terms of speed and amount, dictated the use of a microcontroller. In our case the Motorola 68HC11 CMOS microcontroller integrated circuit was chosen for this purpose thanks to its low power consumption, small size and built-in analog to digital (A/D) converter with 8 input multiplexer.

The A/D converter of the microcontroller converts simple signals into digital values and transfers them to a personal computer with RF circuit via an RS 232 serial port.

The RF module transmits the data through the Amplitude Modulation of $464 \mathrm{MHz}$ frequency, so the consumed power of transmission is $13 \mathrm{~m} \mathrm{~W}$. 


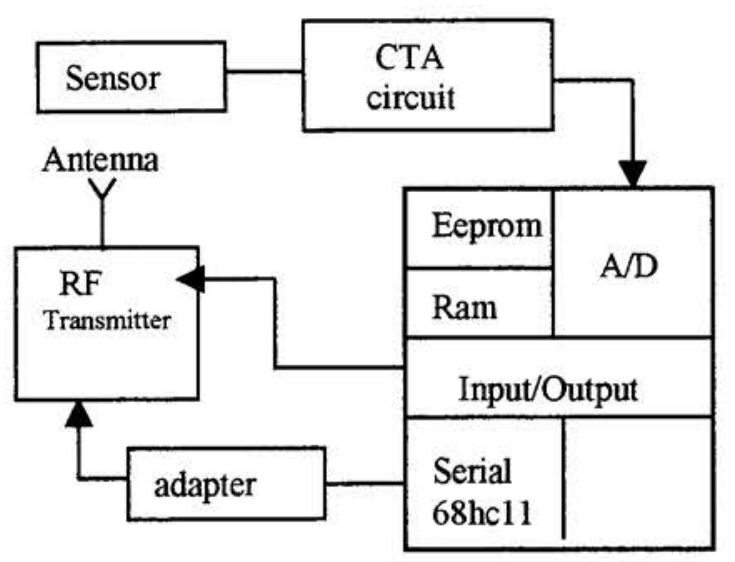

Fig. 5 Block diagrams of the microcontroller data acquisition

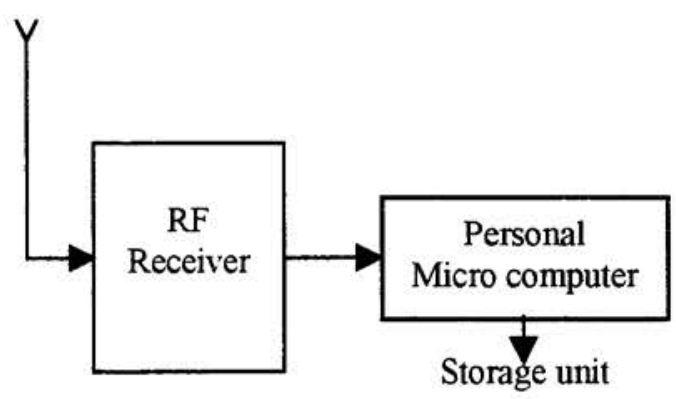

Fig. 6 Schematic diagram of the data receiver in the laboratory

\section{Conditioning circuit}

As shown in Fig. 7, the associated analogue circuit is divided into 3 stages: a Wheatstone bridge circuit. a Constant Temperature Anemometer (CTA) feedback circuit with a power stage and a differential amplifier circuit with an offset compensation network.

The Wheatstone circuit is formed with two precision resistors of $0.01 \%$ accuracy and a tuneable resistor to control the initial voltage reference. In the fourth branch we place the sensor near the resistors and the conditioned circuit in order to minimise the noise and any external perturbations.

The AD620 circuit component, is a low cost, high accuracy instrumentation amplifier which requires only one external resistor to set main gains from 1 to 1000 . This latter is working as preamplifier due to its low voltage noise.

In order to reduce the circuit size, we have pasted the sensor and the Wheatstone bridge on the ceramic support. The conditioning circuit is realized with a very small circuit under the ceramic holder in which the Surface Mounted Circuits (CMS) technology is used.

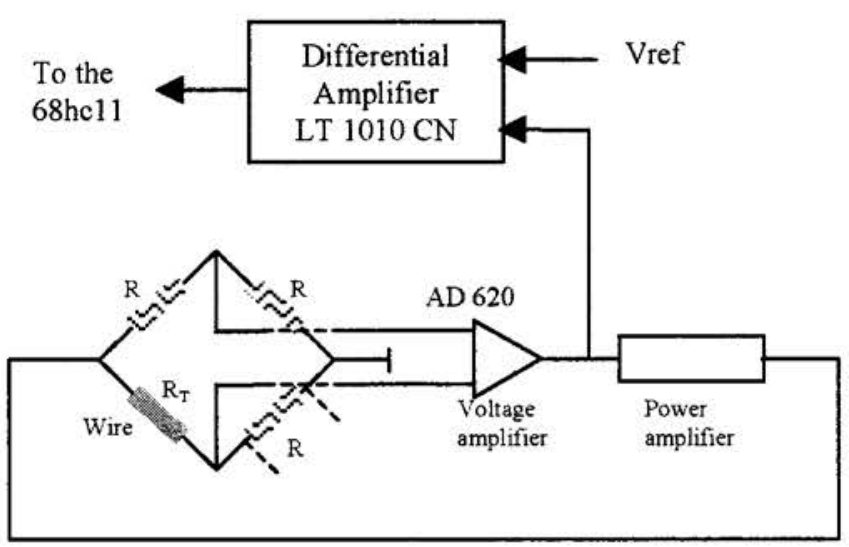

Fig.7 Schematic diagram of hot wire anemometer mounted in Constant Temperature Mode.

The hot wire anemometer is mounted in a Wheatstone bridge: This is a self-balancing bridge which maintains the resistance $R_{T}$ of the sensor at a constant value $R$. An increase in fluid velocity causes a decrease of the temperature $T$ as well as of the $R_{T}$ values inducing an unbalancing of the bridge. This causes the amplifier output current and current through the sensor to increase thereby restoring $T$ and $R_{T}$ to their required values.

The advantage of such CTM circuit [7] is to minimise thermal inertia of the sensors. which was leading to rather bad time response.

\section{STATIC SPEED CALIBRATION}

The sensor was also characterised in a wind tunnel in order to calibrate it for static speed variation.

Experimentally, the hot wire anemometer is mounted at the wall surface of the wind tunnel. A Pitot tube measures the pressure in the centre of the tunnel. This pressure is then transformed in order to know the macroscopic speed. This calibration was performed for velocity ranging from $7 \mathrm{~m} / \mathrm{s}$ up to $15 \mathrm{~m} / \mathrm{s}$.

With this constant temperature configuration, we can find the various parameters $\alpha, \beta$ and $n$ of the electrical calibration of the sensor described by a law as: $E^{2}=\alpha \cdot\left(\overline{u_{\tau}}\right)^{2 n}+\beta[8]$, where $\mathrm{E}$ is the output voltage and $\overline{u_{\tau}} \approx u_{\infty} / 22$ is the friction speed.

In measuring the output voltage variations, we can determine the other coefficients. In Fig. 8, one can see that the above mentioned law fits perfectly the experimental values when $n$ is taken equal to $1 / 3$. This is in very good agreement with the Levêque solution which states that $\mathrm{n}$ coefficient has to be close to $1 / 3$. 


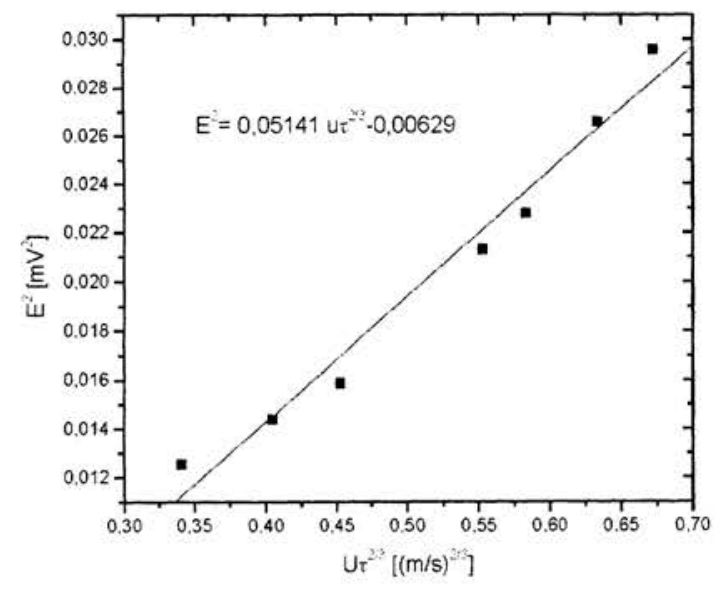

Fig. 8 Static speed calibration in wind tunnel: $\mathrm{E}^{2}$ in function of $\left(\mathrm{u}_{\mathrm{r}}\right)^{2 / 3}$.

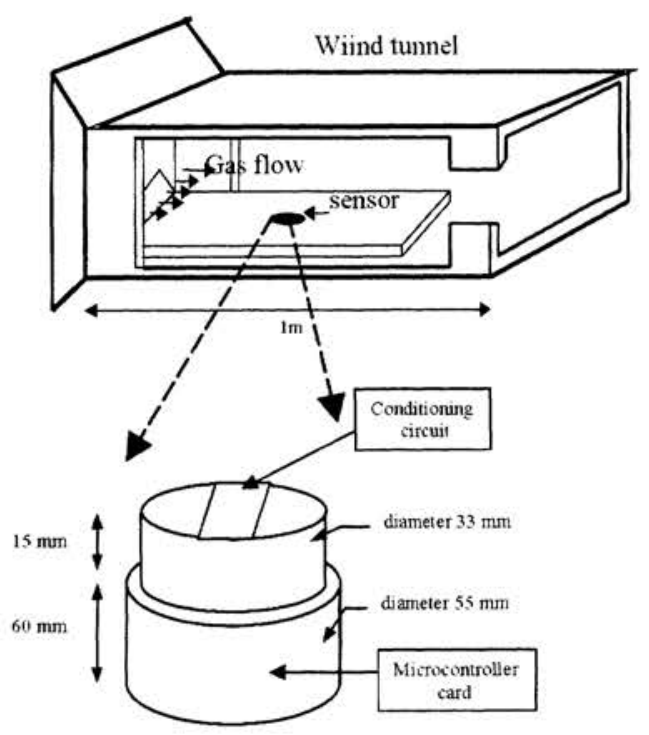

Fig. 9 Schematic diagram of the wind tunnel and the shear stress sensor mounting with data acquisition

\section{CONCLUSION}

Hot wire integrated anemometers obtained with polysilicon material were fabricated and characterised. Very tiny wires suspended upon cavity were on-wafer tested and demonstrated to have a good temperature sensitivity. The TCR value was found on the order of $-0.5 \times 10^{-4} /{ }^{\circ} \mathrm{C}$ and proven to be constant on the whole wafer. Time response with constant current model (CCM) and Constant temperature model (CTM) was measured. The latter gives a value of $150 \mu \mathrm{s}$ which is compatible with the required performance and in good agreement with our previous results obtained by simulation $[4,5,9]$.

\section{REFERENCE}

[1] S. Tardu: Near wall turbulence control for local periodical blowing. Experimental thermal and fluid science. Vol 16 n 1-2. pp.41-53.1998.

[2] D. Meunier. D.Tsamados. J.Boussev. S.Tardu: Simulation of wall shear stress integrated sensors. Therminics,02. Madrid (Spain). Oet 02.

[3] P.C. Stainback. K. A Nagabushana. Review of hot wire Anemometry techniques and the range of their applicability for various flows, Electronic Journal of Fluids Engeenering.

[4] D. Meunier. D.Tsamados, J.Boussey, S.Tardu: Thermo-fluidic FEM simulation of ultra-miniaturised wall shear sensors. Eurosime 03, Aix en provence (France). April 03.

[5] L. Löfdahl: The influence of temperature on the measurements of Reynolds Stresses in shear free turbulence near a wall. Experiments in Fluids 25 (1998) 160-164.

[6] S.Ameur, M. Laghrouche and A.Adane " Monitoring a greenhouse using a microcontroller-based meteorological data acquisition" renewabe energy: vol 24.(2001).19-30.

[7] B.C. Gale: An Elementary Introduction to Hot Wire and Hot Film Anemometry: DISA Technical Publication.

[8] L.V. King: On the convection of heat from small cylinders in a stream of fluid. Philosophical Transactions of Royal Society. Series A. vol. 214. 1914.

[9] F.Jiang. Silicon Micromachined Flow Sensors. Thesis. California Institute of Technology. 1998. 